\title{
LAS EMPRESAS TRANSNACIONALES Y LOS PAÍSES EN DESARROLLO
}

\author{
Por: Alberto Romero ${ }^{1}$ - Mary Analí Vera Colina²
}

\section{RESUMEN}

En el presente artículo se plantea como objetivo la caracterización de las empresas transnacionales (ETN), su importancia a escala global y su impacto en los países en desarrollo. Para ello se sistematiza la información relacionada con el tema, teniendo en cuenta su actualidad y pertinencia. Se concluye que el impacto de las ETNs en los países en desarrollo tiende a ser negativa, debido a las condiciones en que estas desarrollan su actividad.

Palabras clave: Empresas transnacionales, Inversión extranjera, Países en desarrollo, División internacional del trabajo, Globalización.

Clasificación JEL: F23, F21, F20, F60.

1. Doctor en Economía e investigador independiente. Hace parte del Grupo de Estudios Interdisciplinarios sobre Gestión y Contabilidad (INTERGES). E-mail: alromer@gmail.com.

2. Doctora en Ciencias Económicas. Se desempeña como profesora de la Facultad de Ciencias Económicas de la Universidad Nacional de Colombia. E-mail: maaveraco@unal.edu.co. 


\title{
TRANSNATIONAL CORPORATIONS AND DEVELOPING COUNTRIES
}

\author{
Por: Alberto Romero - Mary Analí Vera Colina
}

\section{ABSTRACT}

This article seeks characterization of transnational corporations (TNCs), their importance on a global scale and its impact on developing countries. This information related to the subject is systematized, given its timeliness and relevance. We conclude that the impact of TNCs in developing countries tends to be negative, due to the conditions under which these are active.

Key words: Transnational corporations, foreign investment, developing countries, international division of labor, globalization.

Classification JEL: F23, F21, F20, F60. 


\section{INTRODUCCIÓN}

El análisis del papel de las ETN en el contexto global de la economía se ha vuelto recurrente, debido a su creciente protagonismo e importancia. Las ETN se han convertido en una poderosa fuerza, capaz de influir no solo en el comportamiento de los flujos comerciales y financieros mundiales, sino también en la orientación de las políticas socioeconómicas de los países en desarrollo y en su modelo de inserción en la economía internacional. En el capítulo 1 se realiza una aproximación al concepto de ETN; en el capítulo 2 se resume la importancia económica de las ETNs a escala global. En el capítulo 3 se analiza en profundidad el impacto multidimensional de las ETNs en los países en desarrollo. Finalmente, en el capítulo 4, se desenmascara el contenido real de la llamada responsabilidad social de las empresas transnacionales. Se concluye que el impacto de las ETNs en los países en desarrollo será cada vez más negativo, toda vez que dificulta un desarrollo independiente y más bien supedita este a los intereses del capital extranjero.

\section{APROXIMACIÓN CONCEPTUAL}

En general, una empresa transnacional (ETN) es aquella que extiende sus actividades más allá de su lugar de origen. De acuerdo con Dunning (1993: 1),

Las corporaciones transnacionales son empresas que poseen o controlan actividades de valor agregado en dos o más países. La modalidad usual de posesión y control es a través de las inversiones extranjeras directas (IED), aunque las ETN pueden participar también en la producción foránea a través de alianzas con firmas extranjeras.

El criterio para establecer filiales en otro país, por lo general, es el de aprovechar ciertas ventajas, como mayor flexibilidad jurídica frente al capital extranjero, mano de obra relativamente más barata, entorno macroeconómico y político estable, tipo de cambio favorable, abundancia de recursos naturales, tamaño del mercado interno, entre otros factores.

El proceso de transnacionalización de las empresas va acompañado de un mayor poder financiero, tecnológico y organizacional, y unas instituciones más sólidas, en comparación con los países receptores menos desarrollados. Esta situación coloca a las ETN, en gran medida localizadas en los países más desarrollados, en clara ventaja frente a las economías receptoras de los países en desarrollo, pobres en recursos financieros y en desarrollo tecnológico, pero ricas en recursos naturales y mano de obra relativamente más barata y cada vez más calificada.

Más allá de la definición técnica de lo que representa una ETN, es importante precisar que se trata en su mayoría de empresas de tipo capitalista, grandes y medianas, cuyo interés final es la obtención del máximo beneficio con el mínimo riesgo posible, sin importar las consecuencias sociales, económicas y ambientales que se puedan derivar de su actividad en el país anfitrión. 


\title{
2. IMPORTANCIA DE LAS ETN EN LA ECONOMÍA MUNDIAL
}

\author{
De acuerdo con Dunning y Sauvant (1993: x)
}

The importance of transnational corporations and the globalization of production are now well recognized. Transnational corporations have become central actors of the world economy and, in linking foreign direct investment, trade, technology and finance; they are a driving force of economic growth. Their impact on the economic and social welfare of developed and developing countries is both widespread and critical.

El papel de las ETN en la economía mundial ha venido incrementándose de manera sostenida, en especial a partir de la década del setenta del siglo XX, coincidiendo, según Hutchinson (2003: 4), con la tercera división internacional del trabajo, "la cual se caracterizó por la internacionalización de la producción - a diferencia del comercio entre los países del centro y la periferia", o con la segunda fase de la globalización, llamada por Deneault (2012: 9) "multinacionalización de las corporaciones"3. Su expansión corresponde a la creciente internacionalización de la producción y del capital, intensificada a raíz de los profundos cambios en el desarrollo de las fuerzas productivas, iniciados en el siglo XIX y profundizados a partir de la segunda mitad del siglo XX, con la introducción de nuevas tecnologías en los procesos económicos, sociales, políticos y militares.

En la actualidad, es de común aceptación que las ETN son el motor de la globalización, toda vez que con su accionar han entretejido una compleja red de interrelaciones e interdependencias que tienden a crear la sensación de un todo integrado, son un elemento clave de la integración económica internacional. Permiten "establecer vínculos directos, estables y de larga duración entre economías" y, en condiciones políticas adecuadas, "puede servir como vehículo importante para el desarrollo de la empresa local, y ayudar también a mejorar la competitividad tanto de la economía que los recibe ("receptora") como de la que los invierte ("inversora")" (OCDE, 2010: 8).

La gran empresa, que antes administraba todo el proceso desde su casa matriz, es reemplazada por un sinnúmero de filiales en el extranjero, generándose un creciente intercambio de bienes y servicios intra-firma, donde el producto final es el resultado del ensamblaje de partes elaboradas en diferentes países, con lo cual se va perdiendo el concepto "made in”. Se va gestando así una división sui géneris del trabajo al interior de las mismas, desdibujándose aparentemente el origen de las mercancías que circulan en los mercados mundiales. En el mismo sentido, las cadenas globales de valor son controladas por las ETNs, a través del comercio transfronterizo que tiene lugar dentro de sus redes de afiliadas, socios contractuales y los proveedores, en condiciones de libre competencia (UNCTAD, 2013: 122).

3. Según este autor "During this stage, globalization was characterized by a departure from the concept of internationalization and a shift to foreign direct investment (FDI). The new logic of integration, universalization and deterritorialization superseded the traditional logic of the import-export style of openness" (2012: 9). 
Como resultado de estos trascendentales cambios, la OMC está promoviendo el concepto "hecho en el mundo", para identificar el origen de las mercancías. No obstante, el factor determinante en esta división del trabajo sigue siendo el control, por parte de las ETN, del diseño, la producción, el comercio, los flujos de capital y las innovaciones tecnológicas (Romero y Vera, 2012: 53-54).

Según la UNCTAD (2011b: viii), en 2010 la producción mundial de las ETN generó un valor agregado de 16 billones de dólares, lo que representa la cuarta parte del PIB mundial. A las filiales extranjeras de estas empresas les correspondió el $10 \%$ del PIB y un tercio de las exportaciones mundiales.

En 2011, la segunda economía más grande del mundo, después de los Estados Unidos (cuyo PIB fue de 15,1 billones de dólares), estuvo representada por las 500 empresas más grandes, con un PIB de 11,8 billones de dólares, superior a la suma de los PIB de Alemania, Francia, Brasil y Reino Unido (11,3 billones de dólares en total) ${ }^{4}$. Ya en 2004, las dos mil empresas más grandes del mundo realizaron negocios equivalentes al 60\% del PIB mundial (32 billones de dólares), que acapararon el 85\% de los activos mundiales y obtuvieron beneficios por $760 \mathrm{mil}$ millones de dólares (Romero, 2007, p. 276). En la actualidad (2012), las ventas de las filiales de las ETNs ascienden a cerca de 26 billones de dólares, muy por encima del promedio alcanzado durante 2005-2007 (19,6 billones de dólares), justo antes del comienzo de la crisis. En 2012 los activos totales de las filiales extranjeras de las ETNs sumaban 86,6 billones de dólares, casi el doble que en 2005-2007 (43,8 billones). UNCTAD (2013: xvi, table 2).

Según un estudio realizado por científicos del Polytechnic Institute de Zurich, con base en la data de 43000 corporaciones, un puñado de ETN interconectadas, lideradas por los grandes bancos, tienen un poder de control hegemónico de la economía mundial (Vitali et al, 2011). Para el 2007, los 737 mayores accionistas controlaban el 80\% del valor de todas las ETN (Vitali et al, 2011: 6) y un núcleo conformado por tan solo 147 controlaban el 40\% de ellas ${ }^{5}$. De las 50 empresas más interconectadas, 48 corresponden a Bancos, Fondos de Cobertura y entidades prestadoras de otros servicios financieros ${ }^{6}$. En ese mismo año, de las 2000 empresas listadas por Forbes, 500 realizaron cerca del $66 \%$ de las ventas totales y obtuvieron el $74,5 \%$ de los beneficios ${ }^{7}$.

4. Ver: Fortune 500. If the Fortune 500 were a country.... Recuperado de: http://money.cnn.com/magazines/fortune/fortune500/world-economies-interactive/index.html

5. Ver: Alejandro Teitelbaum. Las sociedades transnacionales. En: Capital transnacional vs Resistencia de los pueblos. América Latina en movimiento, número 476, junio de 2012, p. 7. Recuperado de: http://www.tni.org/sites/www.tni.org/files/download/alai476w.pdf

6. Transnational Institute. State of Power 2014. Exposing the Davos Class. Enero, 2014. Recuperado de: http://www.tni.org/sites/www.tni.org/files/download/state_of_power_hyperlinked_0.pdf

7. Ver: Joan-Eugeni Sánchez. El poder de las empresas multinacionales. X Coloquio Internacional de Geocrítica. Universidad de Barcelona, 26-30 de mayo de 2008. Recuperado de: http://www.ub.edu/ geocrit/-xcol/449.htm 
Según grupos de actividad, las 500 ETN más grandes en el 2006 se distribuían de la siguiente manera: servicios $(50,2 \%)$, industria manufacturera $(31,4 \%)$, minería y petróleo $(9,8 \%)$, energía y agua $(6,0 \%)$ y construcción e ingeniería $(2,6 \%)^{\mathbf{8}}$.

Si comparamos las ETNs (ingresos) con las economías de los países (PIB) se tiene que en 2012, 37 de las 100 economías más grandes del mundo correspondían a las primeras, lo que corrobora la importancia de estas en el contexto internacional ${ }^{\mathbf{9}}$.

\subsection{Las más grandes}

Según Forbes, en 2012 las 2000 compañías globales más poderosas registraban 36 billones de dólares en ventas, 2.6 billones en utilidades, 149 billones en activos y 37 billones en valor de mercado. Las 5 más poderosas en ese año fueron, en su orden, Exxon Mobil (petróleo y gas), JPMorgan (Bancos), General Electric (Conglomerados), Royal Dutch Shell (petróleo y gas) e Industrial \& Comercial Bank of China (Bancos). ${ }^{\mathbf{1 0}}$ En 2013 este orden cambió en favor de China (las dos primeras) y Estados Unidos (las tres restantes) (Ver cuadro 1).

\section{Cuadro 1}

\section{Las 20 ETN más grandes, 2013 (miles de millones de dólares)}

\begin{tabular}{|c|l|l|r|r|r|r|}
\hline Posición & \multicolumn{1}{|c|}{ Compañía } & \multicolumn{1}{|c|}{ País } & Ventas & \multicolumn{1}{c|}{ Utilidades } & Activos & $\begin{array}{c}\text { Valor en el } \\
\text { mercado }\end{array}$ \\
\hline 1 & ICBC & China & 134,80 & 37,80 & $2.813,50$ & 237,30 \\
\hline 2 & $\begin{array}{l}\text { China Construction } \\
\text { Bank }\end{array}$ & China & 113,10 & 30,60 & $2.241,00$ & 202,00 \\
\hline 3 & JPMorgan Chase & $\begin{array}{l}\text { United } \\
\text { States }\end{array}$ & 108,20 & 21,30 & $2.359,10$ & 191,40 \\
\hline 4 & General Electric & $\begin{array}{l}\text { United } \\
\text { States }\end{array}$ & 147,40 & 13,60 & 685,30 & 243,70 \\
\hline 5 & Exxon Mobil & $\begin{array}{l}\text { United } \\
\text { States }\end{array}$ & 420,70 & 44,90 & 333,80 & 400,40 \\
\hline 6 & HSBC Holdings & $\begin{array}{l}\text { United } \\
\text { Kingdom }\end{array}$ & 104,90 & 14,30 & $2.684,10$ & 201,30 \\
\hline 7 & Royal Dutch Shell & Netherlands & 467,20 & 26,60 & $360,3 \mathrm{~B}$ & 213,10 \\
\hline 8 & $\begin{array}{l}\text { Agricultural Bank of } \\
\text { China }\end{array}$ & China & 103,00 & 23,00 & $2.124,20$ & 150,80 \\
\hline
\end{tabular}

8. Ver: Joan-Eugeni Sánchez, Op. cit., cuadro 6.

9. Transnational Institute. State of Power 2014. A Corporate Planet. Enero, 2014. Recuperado de: http://www.tni.org/infographic/planet-earth-corporate-world

10. Ver: Forbes Global 2000 Ranking of the World's Biggest Companies. Mayo de 2013. Recuperado de: http://www.forbes.com/sites/forbespr/2012/04/18/press-release-forbes-global-2000-ranking-ofthe-worlds-biggest-companies/ 


\begin{tabular}{|c|l|l|r|r|r|r|}
\hline Posición & \multicolumn{1}{|c|}{ Compañía } & \multicolumn{1}{|c|}{ País } & Ventas & Utilidades & Activos & $\begin{array}{r}\text { Valor en el } \\
\text { mercado }\end{array}$ \\
\hline 9 & Berkshire Hathaway & $\begin{array}{l}\text { United } \\
\text { States }\end{array}$ & 162,50 & 14,80 & 427,50 & 252,80 \\
\hline 9 & Petro China & China & 308,90 & 18,30 & 347,80 & 261,20 \\
\hline 11 & Bank of China & China & 98,10 & 22,10 & $2.033,80$ & 131,70 \\
\hline 12 & Wells Fargo & $\begin{array}{l}\text { United } \\
\text { States }\end{array}$ & 91,20 & 18,90 & $1.423,00$ & 201,30 \\
\hline 13 & Chevron & $\begin{array}{l}\text { United } \\
\text { States }\end{array}$ & 222,60 & 26,20 & 233,00 & 232,50 \\
\hline 14 & Volkswagen Group & Germany & 254,00 & 28,60 & 408,20 & 94,40 \\
\hline 15 & Apple & $\begin{array}{l}\text { United } \\
\text { States }\end{array}$ & 164,70 & 41,70 & 196,10 & 416,60 \\
\hline 15 & Wal-Mart Stores & $\begin{array}{l}\text { United } \\
\text { States }\end{array}$ & 469,20 & 17,00 & 203,10 & 242,50 \\
\hline 17 & Gazprom & Russia & 144,00 & 40,60 & 339,30 & 111,40 \\
\hline 18 & BP & $\begin{array}{l}\text { United } \\
\text { Kingdom }\end{array}$ & 370,90 & 11,60 & 301,00 & 130,40 \\
\hline 19 & Citigroup & $\begin{array}{l}\text { United } \\
\text { States }\end{array}$ & 90,70 & 7,50 & $1.864,70$ & 143,60 \\
\hline 20 & Petrobras & Brazil & 144,1 & 11,00 & 331,60 & 120,70 \\
\hline 20 & $\begin{array}{l}\text { Samsung Electro- } \\
\text { nics }\end{array}$ & South Korea & 187,80 & 21,70 & 196,30 & 174,40 \\
\hline
\end{tabular}

Fuente: Forbes. Global 2000 Leading Companies. Values calculated May 2013.

http://www.forbes.com/global2000/list/

Como se observa en el cuadro 1, de las 20 principales transnacionales, el 45\% se origina en Estados Unidos, seguidos de China con el 25\%; el resto se distribuye entre Reino Unido, Holanda, Alemania, Rusia, Brasil y Corea del Sur, respectivamente.

En general, la mayoría de las principales ETN tiene su origen en los países desarrollados, en especial Estados Unidos, Inglaterra, Francia, Alemania, Japón, Canadá e Italia. En el 2008 el 72\% del total de las ENTs (82000) se concentraba en las economías desarrolladas, al tiempo que el resto (28\%) tenía su origen en las economías en desarrollo y en transición, aunque éstas últimas han venido adquiriendo cada vez mayor importancia, toda vez que en 1992 su participación era de apenas el 8\% (UNCTAD, 2010: 17).

Uno de los rasgos sobresalientes de las ETN es el control que un pequeño grupo de éstas ejerce sobre las principales actividades económicas en el mundo. Las 10 empresas más grandes del planeta participan en el mercado de los siguientes sectores: industria farmacéutica (55\%), semillas patentadas (67\%), agroquímicos (89\%), alimentos y bebidas (26\%), distribución de comestibles (40\%), biotecno- 
logía (66\%) y farmacéutica veterinaria (63\%), lo cual tiene un impacto negativo en los consumidores (ETC Group, 2008: 4). En 2007, de las ventas realizadas por las 10 mayores industrias de semillas (14,785 millones de dólares), 3 empresas: Monsanto, DuPont y Syngenta, concentraban el 69,5\%. Estas últimas también controlaban el 47\% del mercado mundial de semillas patentadas (ETC Group, 2008: 11). En la industria de agroquímicos, de las 10 empresas que controlan el $89 \%$ de las ventas mundiales, 3 de ellas: Bayer, Syngenta y BASF, sobresalen con el 49\% (ETC Group, 2008: 15).

A escala global, tan solo 10 empresas controlan el consumo masivo mundial de decenas de productos cuyas marcas encontramos en los supermercados, sin preguntarnos quien está detrás de ellas. Estos gigantes son: Pepsico, Coca Cola, Kelloggs, Nestle, Johnson \& Johnson, Procter and Gamble, Mars, Unilever, Kraft y General Mills ${ }^{\mathbf{1 1}}$.

Aún más concentrada es la actividad de las cinco mil mayores ETNs en el extranjero. Por región vemos que en 2008 los países desarrollados acaparaban el 92\% de los activos y el $90.9 \%$ de las ventas en el exterior, destacándose la tríada compuesta por la UE, Estados Unidos y Japón. Al mismo tiempo, las llamadas economías en desarrollo y en transición participaban con apenas el 8 y 9.1 por ciento, respectivamente, aunque muy por encima de similares indicadores en 1995. Los países desarrollados, por su parte, presentaban una disminución en su participación, en comparación con 1995 (Ver cuadro 2).

\section{Cuadro 2}

Actividades en el extranjero de las 5000 mayores ETNs/*, según región, casa matriz y países - 1995 y 2008 (Porcentajes)

\begin{tabular}{|l|r|r|r|r|}
\hline \multirow{2}{*}{ Región casa matriz } & \multicolumn{2}{c|}{$\begin{array}{c}\text { Activos en el ex- } \\
\text { tranjero }\end{array}$} & \multicolumn{2}{c|}{$\begin{array}{c}\text { Ventas en el extran- } \\
\text { jero }\end{array}$} \\
\cline { 2 - 5 } & \multicolumn{1}{c|}{1995} & \multicolumn{1}{c|}{2008} & \multicolumn{1}{c|}{1995} & \multicolumn{1}{c|}{2008} \\
\hline \multicolumn{1}{|c|}{ Países desarrollados } & 98.9 & 92.0 & 98.7 & 90.9 \\
\hline Unión Europea & 27.9 & 40.4 & 37.7 & 40.9 \\
\hline Estados Unidos & 55.5 & 29.5 & 28.0 & 29.1 \\
\hline Japón & 8.8 & 13.3 & 27.8 & 13.9 \\
\hline Economías en desarrollo y en transición & 1.1 & 8.0 & 1.3 & 9.1 \\
\hline De los cuales: Asia & 1.0 & 6.6 & 1.1 & 7.6 \\
\hline Total & 100.0 & 100.0 & 100.0 & 100.0 \\
\hline
\end{tabular}

Fuente: UNCTAD (2010: p. 18, table 1.6).

/* Para 1995 se incluyen solamente 2084 ETNs.

11. Ver: Las 10 empresas que controlan el consumo mundial. Taringa, 15 de mayo de 2012. Recuperado de: http://www.taringa.net/posts/info/14799930/Las-10-Empresas-que-Controlan-el-ConsumoMundial.html 
En el 2006, el 67,4\% de las 500 ETNs más grandes se concentraba en tan solo 6 países (USA, Japón, Francia, Alemania, Reino Unido y China). Si agregamos el grupo conformado por Canadá, Corea del Sur, Holanda, Suiza e Italia, al cual corresponde el 13,4\%, se tiene que 11 países concentran el 80,8\% del total. En comparación con 1996 se observa cómo mientras Japón disminuyó drásticamente su participación el total de las 500, China incrementó la misma en forma significativa ${ }^{\mathbf{1 2}}$.

\subsection{Creciente importancia de las ETN estatales.}

Cabe destacar la creciente importancia de las ETN estatales. Según la UNCTAD (2011b: viii-ix),

Las ETN de propiedad estatal son una nueva e importante fuente de IED. En el mundo hay por lo menos 650 ETN de propiedad estatal, con 8.500 filiales extranjeras. Aunque representan menos del 1\% de las ETN, su inversión en el extranjero representó el 11\% de la IED mundial en 2010.

Para el 2012 el número de ETN estatales ya era de 845 y sus flujos de IED habían aumentado a 145 mil millones de dólares, alcanzando casi el 11\% de la IED global. La mayoría de los activos foráneos adquiridos por las empresas estatales en ese año fueron de los países en desarrollo. Muchas de esas adquisiciones estuvieron motivadas por la búsqueda de activos estratégicos (por ejemplo: tecnología, propiedad intelectual, marcas) y recursos naturales.

La IED acumulada por los llamados fondos soberanos alcanza 127 mil millones de dólares, la cual se ubica en los sectores de finanzas, bienes raíces, construcción y servicios públicos. Más del 70\% de la IED por estos fondos se concentra en los países desarrollados. Se estima que en 2012, el monto de los activos combinados de 73 fondos soberanos alcanzaba la suma de 5,3 billones de dólares, lo que representa un enorme potencial como fuente de financiación del desarrollo (UNCTAD, 2013: xiv).

\subsection{Las multinacionales de los países emergentes}

En las últimas décadas ha crecido la importancia de las ETN de los llamados países emergentes, en especial los del grupo BRICS (Brasil, Rusia, India, China y Suráfrica) $)^{13}$.

De acuerdo con un estudio reciente (Dobbs et al, 2013: 12), para el 2025 el número de las más grandes empresas, con ingresos alrededor de mil millones de dólares, o más, se incrementará en 7000 y la mayoría de estas procederá del mundo

12. Fernando Dorado. Imperio global, transnacionales y estados. ALAI, América Latina en Movimiento. 05 de febrero de 2014. Recuperado de: http://www.alainet.org/active/71061\&lang=es; Joan-Eugeni Sánchez. El poder de las empresas multinacionales. X Coloquio Internacional de Geocrítica. Universidad de Barcelona. Barcelona, mayo de 2008. Recuperado de: http://www.ub.edu/geocrit/xcol/449.htm

13. En general, en las economías en desarrollo se ubica "la mayor parte de la fuerza de trabajo de las filiales extranjeras" y en 2008 eran el origen del $28 \%$ de las 82 mil ETN de todo el mundo. Ver: UNCTAD (2010a: 12). 
emergente. La cantidad de grandes empresas con sede en las regiones emergentes se triplicará y su participación en el total global aumentará del 27 por ciento, hoy en día, a más del 45 por ciento en el 2025, y su participación en los ingresos consolidados se incrementará del 24 al 46 por ciento. Los cambios en la lista de Fortune 500 corroboran esta tendencia. En efecto, entre 1980 y 2000 la participación de compañías localizadas por fuera de las regiones desarrolladas se conservó relativamente estable alrededor del 5 por ciento. Esta participación aumentó al 17 por ciento del total en 2010 y al 26 por ciento en 2013. Con base en el crecimiento proyectado por región se espera que el mundo emergente pase a representar más del 45 por ciento de las empresas de Fortune Global 500 en el 2025, 120 de las cuales se ubicarán en China (Dobbs et al, 2013: 13).

Se estima que en los mercados emergentes están basadas más de 21 mil ETNs, entre las que se destacan empresas como la mexicana Cemex, la Infosys de India, la Embraer de Brasil, las chinas BYD, Huawei, Sinopec, Lenovo, etc. ${ }^{\mathbf{1 4}}$, las cuales compiten de igual a igual con sus similares de los países desarrollados.

\section{Cuadro 3}

\section{Las 25 principales multinacionales emergentes, 2007}

\begin{tabular}{|l|l|c|}
\hline \multicolumn{1}{|c|}{ Empresa } & \multicolumn{1}{c|}{ Industria } & País \\
\hline América Movil & Telecomunicaciones & Brasil \\
\hline Aracruz Celulose & Papel & México \\
\hline Cemex & Cemento & Chile \\
\hline Concha y Toro & Venta al por mayor & Brasil \\
\hline CVRD & Minería & Brasil \\
\hline Embraer & Aviación & México \\
\hline Grupo Modelo & Cerveza & China \\
\hline Haier & Electrodomésticos & Taiwan \\
\hline HTC & Electrónica & Taiwan \\
\hline Hon Hai & Electrónica & Corea \\
\hline Hyundai Heavy Industries & Construcción naval & Corea \\
\hline Hyundai Motor & Automóviles & India \\
\hline Infosys & Técnica & China \\
\hline Lenovo & Computadores & Malasia \\
\hline MISC & Navegación & Brasil \\
\hline Petrobras & Petróleo y Gas & Corea \\
\hline Posco & Acero & India \\
\hline Ranbaxy & Medicamentos & \\
\hline
\end{tabular}

14. Javier Santiso. La década de los países emergentes. MIT Technology Review. Octubre 13 de 2011. Recuperado de: http://technologyreview.es/blog/post.aspx?bid=390\&bpid=27247 


\begin{tabular}{|l|l|c|}
\hline \multicolumn{1}{|c|}{ Empresa } & \multicolumn{1}{c|}{ Industria } & País \\
\hline Reliance & Petroquímica & India \\
\hline Samsung & Electrónica & Corea \\
\hline Sasol & Petróleo y Gas & Suráfrica \\
\hline Grupo Televisa & Mediática & México \\
\hline TSMC & Semiconductores & Taiwan \\
\hline Tenaris & Acero & Argentina \\
\hline Yue Yuen & Calzado & Taiwan \\
\hline
\end{tabular}

Fuente: Elaborado con base en: Seeking Alpha. The World's Top 25 Emerging Market Multinationals. Marzo 19 de 2007. En línea: http://seekingalpha.com/article/29843-the-world-s-top-25-emerging-market-multinationals

\section{IMPACTO DE LAS ETN EN LAS ECONOMÍAS EN DESARROLLO}

\subsection{Características generales}

El impacto de las ETN en las economías anfitrionas depende de las particularidades de estas últimas; no es lo mismo el efecto en un país avanzado que en uno atrasado, o medianamente desarrollado, o como ocurre en las llamadas economías en transición, pertenecientes al antiguo bloque socialista, donde las IED (inversiones extranjeras directas) no son solo una fuente de financiación, sino una poderosa fuerza de reconversión del anterior sistema en una economía de mercado (Iwasaki, 2009: 28). Entre las formas de inversión extranjera (directas, indirectas o de portafolio, etc.) las más importantes son las IED, toda vez que estas se orientan a permanecer por más largo tiempo en el país anfitrión, mediante la creación de nuevas empresas, la compra de las ya existentes o la fusión con las locales. Estas dos últimas constituyen la mayoría de las IED en los países en desarrollo.

El impacto de las ETN depende también de las características del país de donde provienen las inversiones y de las condiciones en que estas ingresan en las economías receptoras. Si se trata de un país en desarrollo, las condiciones de ingreso de una ETN, por lo general, son más favorables, debido a la mayor falta de control sobre las inversiones, mayores beneficios en materia de tributación y giro de utilidades, menores exigencias en materia de impacto ambiental y social, factores de corrupción, etc. En general, se considera que debe existir una serie de determinantes en los países receptores de IED, relacionados con un marco político favorable para la inversión extranjera, acuerdos internacionales y determinantes económicos, como el tamaño y crecimiento del mercado, la estructura del consumo interno, entre otros ${ }^{15}$.

Un aspecto cualitativo a tener en cuenta es que a través de las ETN se transfiere no solo el modo de producir a los países receptores de inversión extranjera, sino

15. Ver en más detalle: UNCTAD. The Role Of International Investment Agreements In Attracting Foreign Directinvestment To Developing Countries. UNCTAD Series on International Investment Policies for Development. New York and Geneva, 2009, p. 8. Recuperado de: http://unctad.org/en/docs/ diaeia20095_en.pdf 
también el modelo consumista imperante en los centros del capitalismo mundial, además del impacto cultural en los ámbitos educativo, ideológico y político, entre otros tantos (Romero y Vera, 2012: 53). De acuerdo con Meyer (2008: 116),

One way to achieve this is to impose their will on the local economy, government, and culture. In many ways, this mirrors the traditional forms of imperialism that centered on the use of religion, education, and language to supplement military force. Through the use of missionaries and educators, imperialist culture was imposed on colonized lands. Influenced by religious zeal or more pragmatic needs to create and control a native labor force, the abolition of indigenous culture began long before the more recent trends of consumerism and the spread of mass media-produced pop culture.

Así se va configurando una periferia acorde a las necesidades del capital transnacional, dentro de la estrategia global de dominación y control de los recursos naturales y de los mercados y, por qué no decirlo, de los gobiernos, concebida por un puñado de potencias económicas.

¿De qué manera las ETN afectan el comportamiento económico de las economías receptoras de inversiones extranjeras? Según Fortanier (2007: 43), estas lo hacen a través de tres mecanismos, a saber: efectos de tamaño, transferencia de habilidades y tecnología y efectos estructurales. Los efectos de tamaño tienen que ver con "la contribución neta de las IED al ahorro y la inversión del país anfitrión, afectando de esta manera la tasa de crecimiento de la base productiva”. En cuanto a la transferencia de habilidades y de tecnología, esto es posible gracias a que "las ETNs están generalmente concentradas en las industrias intensivas en tecnología”, la cual puede "derramarse" a través de la IED "sobre las firmas locales a través de los efectos demostrativos, la migración laboral o los vínculos entre compradores y proveedores". No obstante, su alcance puede ser limitado, debido a que "las tecnologías de las ETNs son a menudo diseñadas para los salarios y los costos de capital de los países industrializados, y pueden no siempre ser apropiadas bajo los precios de los factores prevalecientes en los países en desarrollo” (Fortanier, 2007: 43-44). Claro que la brecha tecnológica que se genere entre el país receptor y el de origen, depende mucho de la capacidad de absorción del primero ${ }^{\mathbf{1 6}}$.

Los efectos estructurales que provoca el ingreso de las ETNs en los países anfitriones pueden producir cambios de tipo horizontal (competencia) ${ }^{17}$ y vertical

16. “...the technology gap between host and home country indicates the absorptive capacity of host country firms. The larger the gap, the less likely are host country firms to have the human capital and technological know-how to benefit from the technology transferred by the multinationals" (Görg y Strobl, 2003: 2).

17. "..los flujos de inversión horizontal ocurren cuando una firma busca economías de escala ubicando una planta en el extranjero para suplir al mercado externo, incurriendo así en costos fijos". Ver: Dennis Sánchez Navarro. Determinantes de los flujos de inversión extranjera directa estadounidense a través de un modelo gravitacional con componente espacial: evidencia para algunos países latinoamericanos. Ensayos sobre Política Económica , 31 (72) (2013), p. 37. Banco de la República, Bogotá, Colombia. 
(vínculos entre compradores y proveedores) ${ }^{\mathbf{1 8}}$. La inversión de las ETNs en las economías receptoras puede contribuir a estimular la competencia, mejorar la asignación de recursos, dinamizar el mercado local y así contribuir al crecimiento económico; sin embargo, debido a su superioridad tecnológica, las ETNs están en mejores condiciones de explotar economías de escala y acceder con mayor facilidad a las fuentes de financiación, con lo cual pueden sacar de la competencia a las firmas locales, especialmente a las más pequeñas. Su desplazamiento puede conducir a la concentración del mercado, a la formación de rentas monopólicas y al "deterioro en la asignación de recursos" y en consecuencia, a la reducción del crecimiento económico (Fortanier, 2007: 44) ${ }^{\mathbf{1 9}}$.

Las ETN, a través de las IED, pueden influir también en la naturaleza de las exportaciones del país receptor. Esto se da, o bien cuando la ETN utiliza al país anfitrión como plataforma de exportación, en cuyo caso "pueden concentrarse en la producción de bienes más sofisticados que los que previamente exportaba aquel”, o bien, transferir conocimientos a las empresas locales de la misma rama industrial, o a los proveedores, facilitando así la actualización del producto (Harding y Javorcik, 2009: 1).

Bajo la influencia de las ETN, las cadenas de suministro en los países receptores tienen a modificarse de acuerdo a los intereses de los inversores extranjeros. Un aspecto importante que se viene configurando en los mecanismos de penetración de las ETN en las economías en desarrollo son las formas no accionariales (FNA), las cuales son cada vez más importantes, al punto que en 2010 generaron ventas por más de 2 billones de dólares, con amplia participación de los países en desarrollo. Estas FNA se refieren básicamente a “... mecanismos que le permiten a las ETN's realizar inversiones y ampliar su portafolio de negocios bajo un esquema en donde se pueden llevar a cabo actividades, participando en las decisiones gerenciales y operativas, agregando de esta forma más valor a su cadena integrada de operaciones a nivel global". ${ }^{20}$ Se trata de

...la fabricación por contrato, la subcontratación de servicios, la agricultura por contrato, las franquicias, la concesión de licencias, los contratos de gestión y otros tipos de relaciones contractuales que permiten a las ETN coordinar actividades en sus cadenas mundiales de valor e influir en la gestión de las empresas de los países receptores sin tener ninguna participación en ellas (UNCTAD, 2011: 17).

Los promotores de esta modalidad de inversión defienden sus bondades, alegando que les permite a los países menos desarrollados generar empleo, aprovechar la

18. Se trata de inversiones que buscan "beneficios derivados de las diferencias relativas de la dotación de factores entre países". Este fenómeno es también conocido como la "separación de la cadena de valor, tercerización (outsourcing), fragmentación, producción en múltiples etapas y especialización intraproducto”. Ver: Dennis Sánchez Navarro, op. cit., p. 38.

19. Para mayor ilustración ver: Blomström y Kokko (1996), Zarsky y Gallagher (2008), Jiménez (2011).

20. Stephanie Osuna. Nuevas tendencias mundiales de inversión: Formas no accionariales de producción. Conapri, Caracas, 10 de agosto de 2011. Recuperado de:

http://www.conapri.org/ArticleDetailIV.asp?articleid=418632\&CategoryId2=14538 
transferencia de tecnología, aumentar la participación en el PIB y el valor agregado, promover la capacidad industrial a largo plazo, etc. En realidad, esta modalidad de inversión es otra forma de condicionar el desarrollo local a los intereses de las ETNs, profundizando su dependencia y vulnerabilidad frente a las oscilaciones de los mercados controlados por estas.

De esta manera se va configurando la especialización de la economía receptora menos desarrollada, de acuerdo con los intereses de la empresa transnacional y no tanto con los requerimientos de un desarrollo local integral y autónomo. Al crear en el país anfitrión empresas tipo maquila, se configuran enclaves de capital extranjero, generadores de empleo precario y débilmente integrados a la economía local.

Además, en comparación con las empresas locales, las ETNs tienen mayor capacidad de maniobra ante eventuales cambios, tales como el mayor control de las fuerzas del mercado (inteligencia de mercado), mayor posibilidad de reaccionar a tiempo ante una situación de crisis, gracias a los encadenamientos hacia atrás y hacia adelante ${ }^{\mathbf{2 1}}$, condicionados por la división del trabajo al interior de las empresas, desde la casa matriz hasta las filiales en el extranjero. Igualmente, la superioridad tecnológica les permite a las ETN diseñar el esquema de control sobre las economías receptoras de IE, de acuerdo con su estrategia expansionista ${ }^{22}$. Toda transferencia de tecnología y habilidades está enmarcada dentro de dicha estrategia y refuerza el carácter apendicular de las economías menos desarrolladas dentro de la actual división internacional del trabajo.

En general, el accionar de las ETN va en contravía del "libre comercio" y lo que buscan con la deslocalización es el máximo beneficio, gracias a las condiciones favorables ofrecidas por los países anfitriones ${ }^{\mathbf{2 3}}$.

Este accionar de las ETNs no sería posible sin el ejército de lacayos al servicio de los grandes capitales internacionales. Como señala el economista John Perkins (2005: 12), son “ejecutivos de las compañías estadounidenses más respetadas que contratan por sueldos casi de esclavos la mano de obra que explotan bajo condiciones inhumanas en los talleres de Asia”. Se trata de los llamados "gánsteres económicos”, los cuales, según el autor, son generosamente pagados para que estafen a países de todo el mundo. Estos individuos canalizan el dinero del Banco Mundial, de la Agencia Internacional para el Desarrollo (USAID) y de otras organizaciones internacionales de «ayuda» hacia las arcas de las grandes corporaciones y los bolsillos del puñado de familias ricas que controla los recursos naturales del

21. Los encadenamientos productivos son considerados una alternativa para la internacionalización de las pequeñas y medianas empresas locales, con notorio éxito en la industria del software en Centroamérica. Ver: Monge (2002: 19-106).

22. Como señalamos en otro escrito “....al trasladar su producción a los países con salarios bajos y atractivos beneficios ofrecidos por los gobiernos locales, se va configurando una especie de división del trabajo sui géneris, donde los países menos desarrollados se especializan en actividades económicas que favorecen, en primera instancia, los intereses de las ETN y sus países de origen, abandonando el mercado interno y supeditando su desarrollo a la estrategia expansionista de las principales potencias" (Romero, 2012: 53).

23. Johannes Maruschzik. Preface of the German edition. The error of Free Trade. En: Paul Craig Roberts. The Failure of Laissez Faire Capitalism and Economic Dissolution of the West. Kindle edition, 2013. 
planeta. Entre sus instrumentos figuran los dictámenes financieros fraudulentos, las elecciones amañadas, los sobornos, las extorsiones, las trampas sexuales y el asesinato. Ese juego es tan antiguo como los imperios, pero adquiere nuevas y terroríficas dimensiones en nuestra era de la globalización (Perkins, 2005: 9).

Pero no son solo los ejecutivos, sino también ciertos economistas al servicio de las ETNs, quienes tratan de justificar su accionar, lo que pone en entredicho su ética profesional ${ }^{24}$. Claro que, como Perkins, no faltan las "ovejas negras" que le quitan el sueño a las transnacionales. Tal es el caso de John Donovan, un ex socio de la petrolera más grande del mundo, la Shell, dedicado a denunciar las maniobras irregulares e ilegales de esta empresa ${ }^{25}$.

\subsection{Impacto social}

Uno de los aspectos más sobresalientes de la presencia de las ETNs en los países en desarrollo es el impacto social, especialmente la violación de los derechos humanos, sobre la cual existen múltiples testimonios. Donde más se manifiesta esta violación es en la explotación y saqueo de los recursos naturales de los países menos desarrollados.

Tal es el caso, por ejemplo, de la mina Canatuan, de la multinacional canadiense TVI Pacific Inc en Filipinas, cuyas operaciones mineras han forzado el desplazamiento de familias indígenas, provocando su desmembramiento; privando a miles de pequeños mineros de sus medios de subsistencia; afectando a los agricultores y a los pescadores que vivían aguas abajo, como consecuencia de la contaminación de los ríos (Derechos y Democracia, 2007). Otro ejemplo es el extractivismo depredador, practicado por las transnacionales en la selva amazónica peruana, donde las comunidades indígenas están siendo desplazadas de sus ancestrales territorios.

Esta situación adquiere visos dramáticos cuando son los gobiernos quienes promueven la explotación irresponsable de los recursos naturales, con el argumento de que esto contribuye a un mayor desarrollo. En Colombia, a nombre de la "locomotora minero-energética", se ha venido expulsando a poblaciones enteras de sus territorios, alterando el equilibrio ecológico y haciendo inviables otras actividades económicas, a no ser que estén ligadas a la actividad extractivista ${ }^{\mathbf{2 6}}$.

En otra actividad, transnacionales como Wal-Mart sustentan su competitividad en la explotación sistemática de sus trabajadores, con salarios bajos, inseguridad laboral y prohibición de sindicatos. "Esos -y las prácticas corruptas- son los ci-

24. Peter J. Boettke And Kyle W. O’Donnell. The Social Responsibility of Economists. George Mason University, Department of Economics. Working Paper No. 13-20, August 14, 2013. Recuperado de: http://papers.ssrn.com/sol3/papers.cfm?abstract_id=2310305

25. Para más información consultar la página de Donovan: Royal Dutch Shell plc.com, en: http:// royaldutchshellplc.com/

26. Ver: Luis Guillermo Guerrero Guevara. La locomotora de la ambigüedad: Sobre los rieles del reformismo social y la concentración capitalista. En: Cien días, No. 76, Septiembre - Noviembre 2012, p. 4. Recuperado de: http://www.cinep.org.co/archivoscinep/Ciendias_76_pdfs/1.Editorial. ciendias76.pdf 
mientos sobre los que Wal-Mart, el minorista más grande del mundo, ha edificado su competitividad y su expansión" ${ }^{27}$. En noviembre de 2013, más de 1 millón 300 mil trabajadores se anotaron una importante victoria contra Wal-Mart, cuando la National Labor Relations Board dictaminó que la gigante minorista había violado la ley al perseguir a quienes protestaron contra la insuficiente paga y las prácticas laborales abusivas ${ }^{\mathbf{2 8}}$. Mientras tanto, la compañía de los Waltons posee un patrimonio de más de 144 mil millones de dólares, el cual supera la riqueza del 40\% de todos los estadounidenses. Solamente en el 2012 Wal-Mart obtuvo $17 \mathrm{mil} \mathrm{mi-}$ llones de dólares en ganancias y su director ejecutivo recibió más de 20 millones por compensación ${ }^{29}$.

Otros ejemplos de violación de los derechos humanos son la explotación en las maquilas centroamericanas. Igualmente está el caso de Adidas, Nike, Puma y Speedo, y sus métodos de esclavitud salarial. Entre las violaciones que se denuncian están: sueldos míseros, horas extras excesivas, empleo de trabajo infantil, contratos laborales desventajosos, precaria asistencia en salud y seguridad, prohibición de sindicatos, entre otros.

La lucha por las fuentes de recursos naturales ha provocado guerras civiles en África y justificado invasiones militares y asesinatos, como en el caso de Iraq y Afganistán, con graves consecuencias para la población local.

Un caso aberrante es el ocurrido recientemente en Bangladesh, donde perecieron más de mil obreras que confeccionaban ropa para multinacionales como El Corte Inglés, Mango y otras, a causa del derrumbamiento del edificio donde trabajaban 3.500 personas, pese a que ya se había alertado sobre el peligro que corrían ${ }^{30}$. La falta de seguridad industrial, el trabajo precario, son posibles gracias a la complicidad del gobierno de Bangladesh, que con su política neoliberal salvaje permite que ocurra este tipo de violación de los derechos humanos.

Otro genocidio fue el provocado por la transnacional Union Carbide en Bhopal, India en 1984, donde murieron 25 mil habitantes de los tugurios y 100 mil quedaron permanentemente envenenados con cianuro, aparte de una cantidad numerosa de personas que viven en suelo envenenado, beben agua envenenada y respiran aire envenenado ${ }^{31}$.

27. Ver: Francisco Rodríguez. La walmartización laboral. Veracruzanos.inf. 4 de noviembre, 2012. Recuperado de: http://www.veracruzanos.info/la-walmartizacion-laboral/

28. Peter Dreier. Labor Board Sides With Workers: Walmart Can't Silence Employees Any Longer. The Nation, November 19, 2013. Recuperado de: http://www.thenation.com/article/177254/labor-boardsides-workers-walmart-cant-silence-employees-any-longer.

29. Ibídem.

30. Daniel Teitelbaum. Los principios rectores sobre las empresas y los derechos humanos: Garantía de la impunidad del poder económico transnacional. En: KaosenlaRed, Sábado, 21 de Septiembre de 2013. Recuperado de: http://kaosenlared.net/especiales/e/tijeretazos-y-recortes-sociales/ item/68890-los-principios-rectores-sobre-las-empresas-y-los-derechos-humanos-garant\%C3\%ADade-la-impunidad-del-poder-econ\%C3\%B3mico-transnacional.html.

31. Kohls, Gary G. The Powers and Abuses of America's Mega-Corporations. Global Research, March 04, 2014. Recuperado de: http://www.globalresearch.ca/the-powers-and-abuses-of-americas-megacorporations/5371901. 
En su afán por proteger sus intereses económicos las ETNs se alían con grupos al margen de la ley, como es el caso de la empresa norteamericana Chiquita Brands en Colombia y su presunta financiación de las llamadas Autodefensas Unidas de Colombia, grupo paramilitar, autor de asesinatos de líderes sindicales en la zona bananera $^{32}$. Un caso reciente es el asesinato de un opositor al megaproyecto minero La Colosa, en Cajamarca, Colombia, a cargo de la transnacional AngloGold Ashanti, de origen surafricano ${ }^{33}$. En ese mismo sentido ha venido actuando la empresa Drummond ${ }^{\mathbf{3 4}}$.

Con el fin de impedir la violación de los derechos humanos por parte de las ETNs, la ONU ha promulgado una serie de "principios rectores", tendientes a regular el accionar de estas empresas, especialmente en los países menos desarrollados ${ }^{\mathbf{3 5}}$. Como lo resume la revista Dinero:

Según las directrices de la ONU, las empresas deben hacerse responsables de evitar la esclavitud, el trabajo infantil y toda otra forma de explotación económica. También deben proporcionar condiciones de trabajo seguras y decentes, en conformidad con los convenios de la Organización Internacional del Trabajo (OIT). Cuando inviertan en otros países, las empresas tienen la obligación de respetar los derechos humanos de la población local. Y cuando se incumple la normativa, es responsabilidad conjunta de las empresas y de los gobiernos establecer las reparaciones ${ }^{\mathbf{3 6}}$.

No obstante, en la práctica estas empresas violan sistemáticamente las convenciones y la normatividad sobre derechos humanos. Esto se hace evidente cuando analizamos la política de las transnacionales farmacéuticas y su monopolio sobre las patentes de medicamentos esenciales para el tratamiento de enfermedades terminales. Empresas como Bayer, hacen todo lo posible para evitar que sus costosos medicamentos puedan ser producidos como genéricos en los países de menores ingresos. Tal es el caso de India, donde se aplican nuevas licencias sobre la propiedad de patentes, con el fin de que empresas locales fabriquen medicamentos genéricos, mucho más baratos y a los cuales puede acceder la población más pobre.

32. Ver: Elespectador.com. Fiscalía reabrió investigación contra Chiquita Brands por financiamiento a 'paras'. 8 de diciembre de 2012. Sair Buitrago. Reapertura de caso Chiquita Brands enreda a seis empresas. El Tiempo, diciembre 09 de 2012. Juan David Laverde Palma. Los 'pecados' de Chiquita Brands. El Espectador.com, 10 de diciembre de 2012.

33. Ver: Carolina Gutiérrez Torres. El 'Loco' que se le opuso a La Colosa. El Espectador.com, 9 de noviembre de 2013. Recuperado de: http://www.elespectador.com/noticias/nacional/el-loco-se-leopuso-colosa-articulo-457492

34. León Valencia. La Drummond contaminadora, paramilitar y tramposa. Semana, 01 de febrero de 2014. Recuperado de: http://www.semana.com/opinion/articulo/leon-valencia-la-drummond-contaminadora-paramilitar-tramposa/375750-3?hq_e =el\&hq_m=321692\&hq_l=41\&hq_v=4c5dbd46d1

35. ONU. Informe del Representante Especial del Secretario General para la cuestión de los derechos humanos y las empresas transnacionales y otras empresas, John Ruggie. 21 de marzo de 2011. Recuperado de: http://www.bibliotecavirtual.info/wp-content/uploads/2011/07/ONU_principios_ rectores_sobre_empresas_y_ddhh.pdf

36. Dinero.com. ¿Cómo proteger los derechos humanos en una economía globalizada? 10 de diciembre de 2012. Recuperado de: http://www.dinero.com/empresas/articulo/como-proteger-derechoshumanos-economia-globalizada/166177 
$\mathrm{Al}$ respecto, un representante de Bayer declara cínicamente que ellos no producen para mercados como la India, sino para pacientes occidentales con capacidad para adquirirlos ${ }^{37}$.

\subsection{Impacto ambiental}

Existen múltiples ejemplos del impacto negativo de las ETN en el ambiente, especialmente mediante la explotación de petróleo, carbón, oro y otros minerales. Motivadas por el auge de los precios de las materias primas, las ETNs han venido influyendo de manera contundente en las economías receptoras menos desarrolladas, como es el caso de Colombia, donde el crecimiento económico cada vez depende más de la mal llamada "locomotora minera", con graves consecuencias para el ambiente, especialmente en las zonas de reserva forestal y en los páramos (principales fuentes hídricas).

Un ejemplo dramático del impacto ambiental negativo, debido a la presencia de las transnacionales del petróleo, es el caso del Delta del Níger ${ }^{\mathbf{3 8}}$. Igualmente está el caso de la BP en el Golfo de México, donde el derrame de crudo de una plataforma petrolera causó enormes estragos ecológicos y por lo cual la transnacional ha tenido que desembolsar grandes cantidades de dinero, sin que esto compense el daño infringido.

Está también el caso de Ecuador, donde la tala indiscriminada de la selva ha hecho desaparecer la fauna, comunidades indígenas tienden a la extinción y los ríos han sido contaminados por el petróleo. Se estima que entre 1971 y 1992, la Chevron Texaco Corp vertió a los ríos más de 18 millones de litros diarios de petróleo, metales pesados y carcinógenos, altamente nocivos para la salud humana y animal (Perkins, 2005: 19).

En este país, la compañía Texaco explotó durante 26 años (1964-1990) la Amazonía ecuatoriana, período durante el cual vertió por lo menos 80 mil toneladas de residuos petroleros, cantidad superior en 87 veces la vertida por la British Petroleum en el Golfo de México en $2010^{39}$. Al salir del Ecuador, esta transnacional dejó tras

37. El Espectador.com. "No creamos medicamentos para indios, sino para quienes pueden pagarlos": Bayer. 24 de enero de 2014. Recuperado de: http://www.elespectador.com/noticias/salud/nocreamos-medicamentos-indios-sino-quienes-pueden-paga-articulo-470652

38. Como señala Amnesty International, "En 2007, un vertido de petróleo destrozó una región del Delta del Níger, sumiendo a la población en la pobreza. Ahora dependen de la tierra contaminada para su sustento, y no tienen acceso regular a agua potable. Con todo, y a pesar de sus enormes beneficios como empresa (28.600 millones de dólares en 2011). Shell se niega a reconocer el desastre, a limpiar la zona y a pagar las indemnizaciones a las comunidades afectadas.” Ver: Amnesty International. Shell ha contaminado el Delta del Níger. Recuperado de: http://web.es.amnesty.org/ shell-delta-del-niger/

39. Se estima que la contaminación de la Chevron en Sucumbíos, Ecuador, "fue varias veces más grave que la provocada por British Petroleum en el Golfo de México y que la de Exxon Valdez en Alaska. En otras palabras, fue el peor desastre petrolero del mundo, del que se tenga memoria". Ver: Emilio Marín. Correa y su justa campaña contra "La mano sucia de Chevron". LA ARENA. COM, edición del 19/9/2013. Recuperado de: http://www.laarena.com.ar/opinion-correa_y_su_justa_campana_contra_la_mano_sucia_de_chevron_-101678-111.html 
de sí enormes daños ambientales y humanos. Se estima que por cuenta del cáncer asociado a la contaminación han muerto 1.041 personas $^{\mathbf{4 0}}$.

En Colombia, en enero de 2013 la Drummond contaminó con 500 toneladas ${ }^{41}$ de carbón la Bahía de Santa Marta, sitio turístico por excelencia, por lo cual fue multada con cerca de 3,6 millones de dólares, suma considerada ínfima si se compara con las enormes ganancias que recibe esta transnacional ${ }^{42}$. La fiscalía considera que para recuperar en parte el daño ambiental causado por la Drummond se requerirá por lo menos 40 años ${ }^{43}$.

Como los anteriores, existen innumerables ejemplos de la acción depredadora de las ETNs en los países en desarrollo, sin que el derecho internacional las obligue a resarcir los enormes daños causados a la sociedad y al medio ambiente.

\subsection{La práctica de evasión fiscal}

Resulta sintomático que incluso las grandes potencias se quejen de la evasión fiscal de las ETNs, debido a la dificultad de los gobiernos para ejercer un control más efectivo sobre la actividad de las mismas, entre otras cosas por la falta de información entre los países anfitriones y porque las grandes corporaciones tienden a situar su centro de operaciones en los llamados paraísos fiscales ${ }^{44}$. Se calcula que por lo menos 21 billones de dólares se esconden en estos paraísos, cifra equivalente al PIB de Estados Unidos y Japón juntos ${ }^{45}$.

Si esto ocurre con los países más desarrollados no es difícil imaginar el saqueo, por esta vía, de colosales recursos de los países en desarrollo, especialmente de los ricos en recursos naturales. En Zambia, por ejemplo, el gobierno estima que pierde 2 mil millones de dólares al año (15\% del PIB), "debido a la elusión fiscal de las empresas que operan en las minas de cobre del país". ${ }^{46}$ Se estima que tan

40. Entorno inteligente.com. ECUADOR: La transnacional Chevron-Texaco contra el pueblo ecuatoriano. 27 de noviembre de 2013. Recuperado de: http://www.entornointeligente.com/articulo/1644317/ ECUADOR-La-transnacional-ChevronTexaco-contra-el-pueblo-ecuatoriano-27112013

41. Otra fuente indica que fueron 1.857 toneladas las vertidas en el mar de Ciénaga en 2013. Ver: Carlos Tromben y Susan Abad. La brasa del carbón. América Economía, 28 de febrero de 2014. En línea: http://www.americaeconomia.com/revista/la-brasa-del-carbon

42. Ver: El Tiempo.com. Multan con \$ 7.000 millones a la Drummond por derrame de carbón. 19 de diciembre, 2013 Recuperado de: http://www.eltiempo.com/economia/ARTICULO-WEB-NEW NOTA INTERIOR-13301935.html. Juan Pablo Calvás. iQué poco vale el mar!. En: El Espectador, 19 de diciembre de 2013 Recuperado de: http://www.elespectador.com/opinion/poco-vale-el-marcolumna-465169.

43. Ver: El Tiempo.com. 40 años tomaría recuperar daño ambiental de la Drummond en Magdalena. 31 de enero de 2014. Recuperado de: http://www.eltiempo.com/justicia/imputacion-de-cargoscontra-funcionarios-de-drummond_13438364-4

44. Ver: Shawn Pogatchnik. Cumbre del G8 se centra en la evasión fiscal. The Associated Press. New Jersey en Español. Junio 18 de 2013. Recuperado de: http://newjersey-spanish.news12.com/cumbredel-g8-se-centra-en-la-evasion-fiscal-1.5509873?firstfree=yes.

45. Ver: José Luis Escario Díaz-Berrío. Depende: La lucha contra el fraude fiscal. Esglobal, 29 de mayo de 2013. Recuperado de: http://www.esglobal.org/depende-la-lucha-contra-el-fraude-fiscal

46. Rabah Arezki, Gregoire Rota-Graziosi y Lemma W. Senbet. Riesgo de fuga de capitales. Finanzas \& Desarrollo, septiembre de 2013, p. 27. Recuperado de: http://www.imf.org/external/Pubs/FT/fandd/ spa/2013/09/pdf/arezki.pdf 
solo en el 2010, los países en desarrollo perdieron entre 859 y 1.138 mil millones de dólares, debido a los flujos financieros ilícitos. Aproximadamente la mitad de estas sumas corresponde a la transferencia de ganancias de las ETNs, lo que implica una pérdida para estos países de más de 100 mil millones de dólares por concepto de ingresos fiscales ${ }^{47}$.

En el caso colombiano, se estima que 47.900 millones de dólares (17\% del PIB), agazapados en los paraísos fiscales, no pagan impuestos ${ }^{48}$. En países como Venezuela y Panamá dichos recursos alcanzan el 100\% de sus PIB, mientras que en Chile, México y Brasil, dicha proporción es del 48\%, 40\% y 24\%, respectivamente ${ }^{49}$.

En México, el Servicio de Administración Tributario detectó 270 empresas multinacionales que "incurren en operaciones fiscales para erosionar la base tributaria o trasladar los beneficios que obtienen en México a otros países con menor carga impositiva" ${ }^{\mathbf{5 0}}$.

\subsection{Las ETN como factor de corrupción}

Son ampliamente conocidas las prácticas de sobornos a que recurren las ETN en los países receptores de inversiones; una de las más recientes es la denunciada por el periódico The New York Times, según la cual la gigante minorista Walt-Mart sobornó a las autoridades mexicanas con el fin de acelerar el otorgamiento de los permisos de construcción ${ }^{51}$. En Colombia, como en otros tantos países, es conocido el fenómeno de la "puerta giratoria", a través de la cual altos ejecutivos de las empresas transnacionales ingresan a la nómina del gobierno de turno, sin que se produzca la censura correspondiente por parte de los organismos de control. Tal es el caso reciente de Luz Helena Sarmiento, directora hasta hace poco de la Agencia Autoridad Nacional de Licencias Ambientales, quien trabajó en El Cerrejón, y es considerada una aliada de las grandes empresas mineras ${ }^{52}$. Como premio a

47. CONCORD. Spotlight on EU Policy Coherence for Development. The real life impact of EU policies on the poor. Report 2013, p. 26. Recuperado de: http://www.concordeurope.org/259-spotlight-oneu-policy-coherence-for-development

48. Se estima que "una parte muy importante de los costos que reportan en Colombia tiene que ver con el pago del servicio de la deuda a esas filiales o casa matriz y esa es la forma de sacar las utilidades sin pagar impuestos”. Ver: Elespectador.com. Gobierno busca poner freno a fraude tributario de algunas multinacionales. Marzo 06 de 2014.

49. Dinero.com. Los dineros fugados en los paraísos fiscales. 29 de septiembre de 2013.

50. El Diario.mx. Empresas extranjeras evaden más al fisco. 02 de febrero de 2014. Recuperado de: http://diario.mx/Economia/2014-01-21_2d1eba2c/empresas-extranjeras-evaden-mas-al-fisco/

51. Ver: David Barstow. Vast Mexico Bribery Case Hushed Up by Wal-Mart After Top-Level Struggle. The New York Times, April 21, 2012. Recuperado de: http://www.nytimes.com/2012/04/22/business/at-wal-mart-in-mexico-a-bribe-inquiry-silenced.html? $r=1$ Recientemente, la transnacional Johnson \& Johnson fue multada por 2.200 millones de dólares, por dar información errónea sobre medicamentes y sobornar para promover sus ventas. Ver: El Espectador.com, noviembre 04 de 2013. Recuperado de: http://www.elespectador.com/noticias/economia/johnson-johnson-multadous2200-millones-articulo-456446

52. Ver: Alfredo Molano B. De Santurbán al Tayrona. El Espectador.com, enero 12 de 2013. Recuperado de: http://www.elespectador.com/opinion/columna-396280-de-santurban-al-tayrona 
su salida, el gobierno la nombró Ministra de Ambiente y Desarrollo Sostenible ${ }^{53}$. Entre los casos más recientes está el de Luis Carlos Villegas, expresidente de la ANDI, nombrado embajador de Colombia en Estados Unidos, después de haber sido acérrimo defensor de la firma del TLC con ese país, el cual tiene al borde de la ruina a los campesinos y en serios problemas a la industria ${ }^{54}$. Igualmente, en 2013 fue nombrado ministro de agricultura el gerente de Indupalma, empresa privada, caracterizada por invadir grandes extensiones de tierra y de paso expulsar a los campesinos de sus propiedades. Como señala Caballero, esta ha sido "una bofetada a la prometida devolución del campo a los campesinos"55. Otro caso es el del actual viceministro de Minas, César Díaz, comprometido con el sector privado y colaborador de la transnacional AngloGold Ashanti ${ }^{56}$. La táctica de la "puerta giratoria" también se presenta a escala global, como en el caso de la ONU, que recluta funcionarios provenientes de las grandes corporaciones ${ }^{57} \mathrm{o}$, al contrario, altos funcionarios de la ONU pasan a hacer parte de las directivas de las transnacionales.

En Estados Unidos no se ha impedido el uso de nicopesticidas, que están acabando con las abejas y los pájaros, alterando de esta manera el equilibrio ecológico, debido a que en el gobierno están funcionarios antes vinculados a Monsanto, conocida productora de estos venenos ${ }^{58}$. Como se anota en una reciente columna,

Monsanto tiene totalmente comprada a la FDA (Food and Drug Administration) de los Estados Unidos, la cual es la que le abre diariamente las puertas a este gigantesco genocida mundial. Además han infiltrado a su gente en las filas de la FDA, o viceversa, algo que ellos llaman "revolving doors" o "puertas giratorias", que significa pasar gente de Monsanto a la FDA y pasar gente de la FDA a Monsanto. Esto se da también en muchos otros casos y ramos, como en el sector de la bancocracia elitista de Wall-Street y el gobierno estadouni-

53. Ver: MinAmbiente. Recuperado de: http://www.minambiente.gov.co/contenido/contenido. aspx?catID $=463 \&$ conID $=1499$

54. Como sostiene Daniel Samper, "Curiosos premios confiere el Gobierno en su política de intercambio de camisetas entre el sector público y el empresarial”. Ver: Daniel Samper Pizano. Si usted fuera campesino... En: El Tiempo.com, 25 de agosto de 2013

55. Antonio Caballero. El opio de los gobernantes. Semana, 28 de septiembre de 2013. Recuperado de: http://www.semana.com/opinion/articulo/el-opio-de-los-gobernantes/359082-3

56. Carolina Gutiérrez Torres. ¿Por qué el viceministro de Minas no le gusta a los ambientalistas? En: ElEspectador.com, 26 de noviembre de 2013. Recuperado de: http://www.elespectador.com/noticias/ nacional/el-viceministro-de-minas-no-le-gusta-los-ambientalistas-articulo-460502

57. Por ejemplo, "Alexandra Guáqueta, asesora de la empresa Cerrejón y representante de ésta ante el Comité Minero Energético del Programa Presidencial de DDHH y DIH del gobierno colombiano, que reúne a empresas y Fuerza Pública, así como funcionaria de la Oxy Petroleum en Colombia, se ha convertido en la representante de América Latina del exclusivo Grupo de Trabajo de la ONU sobre Empresas Transnacionales y Derechos Humanos”. Ver: Cientos de organizaciones critican a Naciones Unidas por su apoyo a destructivas empresas. ADITAL, 20 de octubre de 2012. Recuperado de: http://www.adital.com.br/site/noticia.asp?lang=ES\&cod=71434 . Ver también: Mapuexpress- Informativo Mapuche. Exigen a organismos ONU un rol activo y resolutivo ante violaciones DDHH de transnacionales. Agosto 26 de 2013. Recuperado de: http://www.mapuexpress. net/?act $=$ news\&id $=10837$

58. Daniel Samper Pizano. La campesina más silenciosa y amenazada. El Tiempo.com, agosto 31 de 2013. 
dense, que generalmente la mayor parte de los miembros del departamento del tesoro han trabajado para Goldman Sachs ${ }^{\mathbf{5 9}}$.

Y es que en Estados Unidos las grandes corporaciones multinacionales han corrompido profundamente el sistema legislativo, con la complicidad del poder judicial. La compra de políticos y la financiación de campañas publicitarias para "lavar" el cerebro de los votantes, es la práctica común de estas empresas. Como compensación, se benefician con leyes que favorecen sus intereses económicos ${ }^{\mathbf{6 0}}$. En este sentido actúa el complejo sistema de cabildeo, por parte de las grandes corporaciones, para obtener jugosos contratos y exenciones tributarias por parte de los gobiernos ${ }^{\mathbf{6 1}}$.

Otro ejemplo de cómo las ETNs no escatiman esfuerzos ni medios para alcanzar sus propósitos es el del desvío de río Ranchería en la Guajira, por parte de funcionarios de El Cerrejón, los cuales recurren a todo tipo de sobornos con el fin de ganar el apoyo de la etnia wayúu ${ }^{62}$. Algo similar ocurrió con un dirigente indígena que interpuso una tutela para tumbar la declaratoria de reserva natural al Parque Nacional Natural Yaigojé Apaporis en el Amazonas colombiano (donde existen importantes yacimientos de oro), el cual, según sus propias declaraciones, recibió asesoría y beneficios de la empresa canadiense Cosigo Resources ${ }^{63}$.

Además, como se señala en un informe de Transparencia Internacional,

...la mayoría de las 42 compañías de petróleo y gas evaluadas no hacen esfuerzos suficientes para reportar sobre pagos que efectúan a los gobiernos receptores, país por país, o para divulgar la información relativa a sus operaciones y a sus programas anticorrupción ${ }^{64}$.

59. Ecoportal.net. Radiografía a Monsanto: La multinacional que atenta contra la salud mundial. Septiembre 03 de 2013. Recuperado de: http://www.ecoportal.net/Temas_Especiales/Globalizacion/ Radiografia_a_Monsanto_La_multinacional_que_atenta_contra_la_salud_mundial

60. Gary G. Kohls. The Powers and Abuses of America's Mega-Corporations. Global Research, marzo 04 de 2014. Recuperado de: http://www.globalresearch.ca/the-powers-and-abuses-of-americasmega-corporations/5371901

61. Como se resalta en un reciente informe, "With more than 700 entities, more than 120 million Euros annual spending and at least 1700 lobbyists at their disposal, the financial lobby is clearly a powerful voice" (Corporate Europe Observatory, 2014, p. 21).

62. Como señala Collazos, "La multinacional carbonífera ha preferido la sutileza disuasiva de dividir para reinar. Su método es más "civilizado", pero está basado en la indignidad ética de valerse de una posición de fuerza económica para vulnerar el derecho a la unidad solidaria. La diferencia entre disuadir y corromper no es mucha". Ver: El Tiempo, noviembre 08 de 2012, p. 20.

63. Pablo Correa. Indígena acepta que minera lo asesoró para 'tumbar' Parque Nacional Yaigojé-Apaporis. El Espectador. 03 de febrero de 2014. Recuperado de: http://www.elespectador.com/noticias/nacional/indigena-acepta-minera-asesoro-tumbar-parque-nacional-y-articulo-472426

64. Transparencia Internacional (2008). Promover la transparencia en los ingresos. Informe 2008 sobre la Transparencia en los Ingresos Provenientes de las Compañías de Petróleo y Gas. Recuperado de: http://files.transparency.org/content/download/165/663/file/2008_PRT_ES.pdf 
En general, el acceso a la información sobre las actividades de las ETNs en los países receptores es bien limitado, lo cual dificulta establecer con precisión sus alcances y su impacto ${ }^{65}$.

Existe a nivel internacional la iniciativa EITI (Extractive Industries Transparency Initiative), con la cual se busca una mayor transparencia de las relaciones entre los gobiernos y las empresas en los países que extraen recursos naturales. Para poder hacer parte de la iniciativa, los países deben cumplir con el llamado estándar de la EITI, el cual consta de dos exigencias: Primero, las empresas deben publicar lo que pagan y los gobiernos publicar lo que reciben en un informe EITI y segundo, este proceso debe ser supervisado por un grupo de multipartícipes (gobierno, empresas y la sociedad civil) ${ }^{\mathbf{6}}$. En la actualidad existen solo 21 países cumplidores de esta iniciativa, entre los cuales en Suramérica solo aparece Perú, presionado por intensos conflictos mineros, como el de Cajamarca. Colombia, supuestamente está en proceso de adhesión a esta iniciativa, sin embargo, este se encuentra estancado ${ }^{67}$.

Los bancos transnacionales no se quedan atrás en materia de corrupción. Tal es el caso del HSBC, denunciado y enjuiciado recientemente en los Estados Unidos por lavado de dineros del narcotráfico ${ }^{68}$. En igual sentido ha sido sancionado JPMorgan Chase, en cuya agenda está el fraude, la corrupción, el lavado de dinero, el robo y la apropiación de riqueza, mediante la manipulación del mercado ${ }^{\mathbf{6 9}}$.

\subsection{Complicidad e incompetencia de los gobiernos}

En gran medida, el impacto negativo de la presencia de las ETN en los países menos desarrollados se debe a la negligencia y corrupción de los gobiernos de turno. Varios ejemplos, como el caso de la mina de níquel de Cerromatoso en Colombia que, según la contralora general de la república, Sandra Morelli, no tiene licencia ambiental vigente y opera con permisos amparados en una ley que fue declarada inconstitucional desde hace más de una década ${ }^{70} \mathrm{y}$, como si fuera poco, el gobierno colombiano le otorgó a la BHP Billiton una prórroga del contrato hasta el 2040, cuando inicialmente estaba hasta el $2029^{71}$. Otro caso preocupante es el

65. Ver por ejemplo: Marco Vinicio Pinzón (2204). Informe final proyecto de investigación "inventario de empresas transnacionales en Colombia” Diciembre 2003-marzo 2004. PASC. Recuperado de: http://www.pasc.ca/en/node/2482

66. Ver: EITI. Hoja informativa 2013. Recuperado de: : http://eiti.org/files/eiti-fact-sheet-spanish.pdf

67. Ver: Andrés Bermúdez Liévano. Colombia, todavía lejos del club de transparencia minera. En: Lasillavacía, mayo 22 de 2013. Recuperado de: http://www.lasillavacia.com/historia/historiamineria-44092

68. Tom Burghardt. Fraud, Money Laundering and Narcotics. Impunity of the Banking Giants. No Prosecution of HSBC. Global Research, December 31, 2012. Recuperado de: http://www.globalresearch.ca/fraud-money-laundering-and-narcotics-impunity-of-the-banking-giants-no-prosecutionof-hsbc/5317406

69. Michel Chossudovsky. Suicides of Bank Executives, Fraud, Financial Manipulation: JPMorgan Chase Advisor Tony Blair is Not Involved. Global Research. Febrero 14 de 2014. Recuperado de: http://www.globalresearch.ca/suicides-of-bank-executives-fraud-financial-manipulation-jpmorganchases-advisor-tony-blair-is-not-involved/5368627

70. Cerro Matoso no cuenta con licencia ambiental. En: Dinero.com, 4 de octubre de 2012.

71. Juan Gossaín. Minería del níquel en Córdoba: entre el oro y la miseria. En: El Tiempo, 05 marzo de 2013. 
del páramo de Santurbán, en Santander, donde las autoridades ambientales han venido recortando el área protegida para favorecer los intereses de las empresas transnacionales explotadoras del oro, poniendo en riesgo el entorno natural y el suministro de agua a las poblaciones adyacentes.

Con el argumento de que la minería es la "locomotora" del crecimiento, los últimos gobiernos han venido incrementando las gabelas a las ETNs, al punto que, según los indicadores, el Estado terminaría pagando para que se lleven los recursos naturales, como ocurre con el carbón. De acuerdo con un reciente informe, con el dinero que Colombia deja de cobrarle a las empresas, por concepto de impuestos, se podría cubrir en parte la deuda social que tiene el Estado con la población más pobre $^{72}$. Se estima que en 2009 el gobierno colombiano perdió 3,8 billones de pesos, equivalentes al 53\% (incluyendo las exenciones a hidrocarburos) de su potencial ingreso por concepto de impuesto a las ganancias de las empresas transnaciona$\operatorname{les}^{73}$. Como señala el informe citado, "en el 2007 las exenciones fiscales para el carbón y los minerales ascendieron a 53 por ciento de los ingresos adeudados. Para el año 2009 esa cifra aumentó drásticamente a 90 por ciento, lo que significa que después de aplicadas las exenciones Colombia sólo recibe el 10 por ciento de la tarifa publicada" ${ }^{\prime 4}$.

A tal punto llega la complicidad con las ETN que, como ocurre en Colombia, el gobierno está destruyendo toneladas de semillas nativas, por no estar certificadas por multinacionales como Monsanto, Dupont y Syngenta, poniendo a los campesinos pobres (que son la mayoría) en seria desventaja para competir. ${ }^{75}$ Con argumentos de tipo sanitario, el ICA les prohíbe a los campesinos producir sus propias semillas, protegiendo así la propiedad industrial de las empresas que las manufacturan. A los que no cumplen se les sanciona hasta con multas muy superiores a las que se impone a los cultivadores de coca o marihuana ${ }^{76}$. Debido a la presión del paro campesino, el gobierno se vio obligado a "congelar" la norma 9.70, que contempla la penalización por utilizar semillas no certificadas ${ }^{77}$.

Refiriéndose a la actividad de la empresa norteamericana Drummond en Colombia, Kalmanovitz señala: "La empresa de Alabama tiene un largo historial de desobediencia de las leyes laborales, de perjudicar la salud de los lugareños donde realiza su explotación a cielo abierto, de daño mayúsculo al medio ambiente

72. ABColombia. Regalándolo Todo: Las Consecuencias de una Política Minera No Sostenible en Colombia. Noviembre de 2012, p. 22. Recuperado de: http://www.abcolombia.org.uk/downloads/ Giving_it_Away_mining_report_SPANISH.pdf

73. Ibídem.

74. Ibídem.

75. Semana. La historia detrás del 970. 24 de agosto de 2013. Recuperado de: http://www.semana. com//nacion/articulo/la-historia-detras-del-970/355078-3

76. Jorge Orlando Melo. ICA: semillas de ira. El Tiempo, 28 de agosto de 2013. Recuperado de: http:// www.eltiempo.com/opinion/columnistas/jorgeorlandomelo/ica-semillas-de-ira-jorge-orlando-melocolumnista-el-tiempo_13026064-4

77. El Tiempo.com. Congelan la norma 970 que penaliza uso de semillas no certificadas. Septiembre 04 de 2013. Recuperado de: http://www.eltiempo.com/politica/acuerdos-entre-gobierno-y-campesinosen-tunja_13047442-4 
y de evasión de las leyes tributarias de un país supuestamente soberano"78. Otro ejemplo, que ilustra la complicidad de los gobiernos con las transnacionales, es el caso de la empresa estadounidense Cargill, la cual ha venido adquiriendo grandes extensiones de tierra en la llamada Altillanura colombiana (Oxfam, 2013).

En el siguiente recuadro se puede observar el comportamiento irresponsable de algunas ETNs.

\subsection{Las más villanas}

\section{Recuadro 1}

\section{LAS 26 MÁS VILLANAS}

\begin{tabular}{|c|c|c|}
\hline Empresa & País de origen & Daño causado \\
\hline Apple & USA & Explotación laboral en condiciones de trabajo precario \\
\hline Bank of America & USA & $\begin{array}{l}\text { Fraude hipotecario, cobro exagerado a los clientes, en- } \\
\text { gaño a los clientes y a los inversionistas, }\end{array}$ \\
\hline BNP Paribas & Francia & $\begin{array}{l}\text { Cobro exagerado a los clientes, fraude con las materias } \\
\text { primas, energía nuclear. }\end{array}$ \\
\hline $\mathrm{BP}$ & Reino Unido & $\begin{array}{l}\text { Contaminación ambiental (Alaska, Golfo de México), } \\
\text { manipulación de precios. }\end{array}$ \\
\hline Chevron & USA & $\begin{array}{l}\text { Contaminación sistemática del ambiente con los de- } \\
\text { rrames de petróleo, violación de los derechos huma- } \\
\text { nos. }\end{array}$ \\
\hline Citigroup & USA & Fraude de WorldCom y Enron, fraude hipotecario. \\
\hline Exxon Mobil & USA & $\begin{array}{l}\text { Derrames de petróleo (Alaska, Río Yellowstone), frac- } \\
\text { turamiento hidráulico (fracking), sobornos, violación } \\
\text { de los derechos humanos. }\end{array}$ \\
\hline HSBC Holdings & Reino Unido & $\begin{array}{l}\text { Lavado de dinero sucio, fraude hipotecario, evasión de } \\
\text { impuestos. }\end{array}$ \\
\hline $\begin{array}{l}\text { ICBC Industrial } \\
\text { and Commercial } \\
\text { Bank of China }\end{array}$ & China & Daño ambiental (Ethiopía) \\
\hline JPMorgan Chase & USA & $\begin{array}{l}\text { Fraude con hipotecas, derivados, consumer fees y bo- } \\
\text { nos municipales para financiar a Enron y WorldCom. }\end{array}$ \\
\hline $\begin{array}{l}\text { Mitsubishi UFJ } \\
\text { Financial }\end{array}$ & Japón & $\begin{array}{l}\text { Fijación de precios, toxicidad de tierras raras en Mala- } \\
\text { sia y otros impactos ambientales. }\end{array}$ \\
\hline
\end{tabular}

78. Salomón Kalmanovitz. La Drummond desafía la ley. Elespectador.com. 12 de enero de 2014. Recuperado de: http://www.elespectador.com/opinion/drummond-desafia-ley-columna-468132 


\begin{tabular}{|c|c|c|}
\hline Empresa & País de origen & Daño causado \\
\hline Mizuho Financial & Japón & $\begin{array}{l}\text { Engaño a los inversionistas, asociación con los sindica- } \\
\text { tos del crimen. }\end{array}$ \\
\hline $\begin{array}{l}\text { PetroChina and } \\
\text { Sinopec }\end{array}$ & China & $\begin{array}{l}\text { Violación de los derechos humanos, participación en } \\
\text { el daño ambiental de Sudán, fugas de gas, explosiones } \\
\text { de oleoductos y fábricas de plásticos (China). }\end{array}$ \\
\hline $\begin{array}{l}\text { Royal Bank of } \\
\text { Scotland }\end{array}$ & Reino Unido & $\begin{array}{l}\text { Fraude hipotecario, manipulación de los mercados (Li- } \\
\text { bor y fijación de precios en los mercados de derivados) }\end{array}$ \\
\hline $\begin{array}{l}\text { Royal Dutch } \\
\text { Shell }\end{array}$ & Holanda & $\begin{array}{l}\text { Derrame de petróleo y violación de los derechos hu- } \\
\text { manos (Nigeria), preocupación por la seguridad en la } \\
\text { perforación petrolera en el Ártico. }\end{array}$ \\
\hline $\begin{array}{l}\text { Samsung } \\
\text { Electronics }\end{array}$ & Corea del Sur & $\begin{array}{l}\text { Escándalo por patentes, Explotación laboral en con- } \\
\text { diciones de trabajo precario (Brasil), acusaciones por } \\
\text { soborno, evasión fiscal y fijación de precios. }\end{array}$ \\
\hline Total & Francia & Esclavitud laboral (Burma), Sobornos (Italia, Iraq) \\
\hline $\begin{array}{l}\text { Volkswagen } \\
\text { Group }\end{array}$ & Alemania & $\begin{array}{l}\text { Espionaje corporativo, escándalo por soborno y co- } \\
\text { rrupción (Alemania, Brasil, India) }\end{array}$ \\
\hline Walt-Mart Stores & USA & $\begin{array}{l}\text { Explotación laboral en condiciones de trabajo preca- } \\
\text { rio, daño ambiental. }\end{array}$ \\
\hline De Beers & Suráfrica & $\begin{array}{l}\text { Financia y promueve guerrillas y dictaduras para la ex- } \\
\text { plotación de niños y adultos en las minas de diaman- } \\
\text { tes, obligando a desplazarse de sus tierras a los aborí- } \\
\text { genes, como ocurre en Botswana. }\end{array}$ \\
\hline Phillip Morris & USA & $\begin{array}{l}\text { El mayor fabricante de cigarrillos, cuyo consumo pro- } \\
\text { duce cáncer en millones de personas en el mundo. }\end{array}$ \\
\hline Coca-Cola & USA & $\begin{array}{l}\text { Contamina las aguas adyacentes a sus plantas, con- } \\
\text { sume tres litros de agua por cada litro producido, y } \\
\text { produce efectos negativos (obesidad) en la salud de } \\
\text { la gente. }\end{array}$ \\
\hline Pfizer & USA & $\begin{array}{l}\text { Experimenta no solo en animales, sino también en se- } \\
\text { res humanos, incluyendo niños, muchos de los cuales } \\
\text { mueren o adquieren enfermedades psíquicas y físicas, } \\
\text { como ocurrió en Nigeria en 1996. También se le acusa } \\
\text { de contaminar el ambiente y sobornar a los médicos y } \\
\text { a los gobiernos para que receten sus medicamentos. }\end{array}$ \\
\hline Mc Donalds & USA & $\begin{array}{l}\text { Utiliza, entre otros, pollos criados artificialmente con } \\
\text { hormonas y antibióticos. Los componentes de los pro- } \\
\text { ductos de McDonalds producen enfermedades, sobre } \\
\text { todo en los niños, como sobrepeso y diabetes. }\end{array}$ \\
\hline
\end{tabular}




\begin{tabular}{|c|c|l|}
\hline Empresa & País de origen & \multicolumn{1}{|c|}{ Daño causado } \\
\hline Nestlé & Suiza & $\begin{array}{l}\text { Deforestación para el cultivo de palma de aceite, pro- } \\
\text { mueve el consumo de leche de fórmula, en lugar de } \\
\text { la leche materna, con el consecuente perjuicio para la } \\
\text { salud de los bebés. }\end{array}$ \\
\hline Monsanto & USA & $\begin{array}{l}\text { Fomenta el cultivo y consumo de alimentos genética- } \\
\text { mente modificados, el uso de hormonas de crecimien- } \\
\text { to bovino, el envenenamiento por agrotóxicos; obliga } \\
\text { al campesino a comprar semillas "certificadas" y pro- } \\
\text { hibirle usar las suyas; produce el tristemente famoso } \\
\text { agente naranja, usado en Vietnam contra la población; } \\
\text { produce pesticidas y herbicidas nocivos para la salud } \\
\text { de las personas. }\end{array}$ \\
\hline
\end{tabular}

Fuente: Elaborado con base en: Transnational Institute. State of Power 2014. A Corporate Planet. 2014. En línea: http://www.tni.org/print/infographic/planet-earth-corporate-world. Ecoportal.net. Las 10 multinacionales más peligrosas del mundo. 30 de octubre de 2012. En línea: http://www.ecoportal.net/Temas_Especiales/ Globalizacion/Las_10_multinacionales_mas_peligrosas_del_mundo.

Como se observa en el recuadro 1, de las 26 ETNs que hemos escogido entre las más villanas, 12 corresponden a Estados Unidos (46,1\%). Se trata de empresas que contaminan el ambiente y violan los derechos humanos (petroleras, mineras), o explotan en condiciones infrahumanas la fuerza de trabajo de los países menos desarrollados, o producen sustancias perjudiciales para la salud humana, o de laboratorios que especulan con las medicinas, o de entidades financieras que especulan con las hipotecas y generan burbujas inmobiliarias, que lavan dineros del narcotráfico y evaden impuestos, o de empresas que sobornan a los funcionarios públicos para obtener contratos o exenciones tributarias, etc.

\section{LA MAL LLAMADA RESPONSABILIDAD SOCIAL DE LAS ETN}

El concepto de responsabilidad social empresarial (RSE) se refiere al compromiso voluntario, formal, que asumen las empresas con su entorno en los aspectos ético, económico, social y ambiental, en la mayoría de los casos como una táctica de marketing para encubrir el impacto negativo de su accionar en los países donde llevan a cabo sus actividades.

Las ETN han venido cambiando de táctica para tratar de mejorar su deteriorada imagen, invirtiendo pequeños recursos (en comparación con las enormes utilidades que reciben de su actividad empresarial) en proyectos de aparente impacto social y ambiental, apoyadas en ONGs especialmente creadas para tal fin, como es el caso de AVINA, dirigida por personas que han sido altos directivos de transnacionales como Nestlé y DuPont ${ }^{79}$. Como señala The Economist,

79. Ver: Organizaciones sociales y ambientales latinoamericanas y españolas denuncian las consecuencias de la actividad de fundaciones supuestamente filantrópicas En: Ecologistas en acción. Recuperado de: http://www.ecologistasenaccion.org/article23123.html 
for a number of reasons, companies are having to work harder to protect their reputation - and, by extension, the environment in which they do business. Scandals at Enron, WorldCom and elsewhere undermined trust in big business and led to heavy-handed government regulation. An ever-expanding army of non-governmental organisations (NGOs) stands ready to do battle with multinational companies at the slightest sign of misbehavior ${ }^{\mathbf{8 0}}$.

De hecho, la "preocupación” por la conservación del medio ambiente se está convirtiendo en un lucrativo negocio para las grandes empresas, enmarcado dentro de lo que se ha dado en llamar "economía verde", a partir de principios mercantilistas $^{\mathbf{8 1}}$. Mediante estrategias publicitarias, como el llamado "greenwashing", o "lavado verde", las ETNs buscan hacer creer al público su compromiso con el ambiente, cuando al mismo tiempo, como en el caso de la Shell, batallan por concesiones petroleras en zonas de alto riesgo ${ }^{\mathbf{8 2}}$. En Colombia, empresas como Pacific Rubiales publicitan las "bondades" que representan para sus trabajadores y el entorno donde explotan petróleo y la Cerro Matoso, explotadora de níquel, igualmente pregonan su compromiso con Colombia, mientras las poblaciones aledañas sobreviven en condiciones de atraso socioeconómico extremo. ${ }^{\mathbf{8 3}}$ En general, el slogan de "responsabilidad social empresarial", "no solamente no representa regulación alguna para las ETN sino que se convierte en una forma de legitimación de sus actividades. En la práctica, una estrategia de mercadeo que se constituye en una verdadera campaña publicitaria, actualmente en curso en todo el mundo"84.

Según Porter y Kramer (2011: 3), las ETNs "han sido vistas cada vez más como una causa importante de los problemas sociales, ambientales y económicos. Hay una percepción muy amplia de que las compañías prosperan a costa del resto de la comunidad.....La legitimidad de las empresas ha caído a niveles inéditos en la historia reciente.....Las empresas están atrapadas en un círculo vicioso". Los autores critican la mentalidad de la "responsabilidad social" "donde los problemas sociales están en la periferia, no en el centro", y proponen como alternativa de solución el "principio de valor compartido":

80. The Economist. Just good business. Enero 17 de 2008. Recuperado de: http://www.economist.com/ specialreports/PrinterFriendly.cfm?story_id $=10491077$

81. Ver, por ejemplo: Pilita Clark. Environment: Capitalist conservationists. En: Financial Times, June 4, 2012. Recuperado de: http://www.ft.com/intl/cms/s/0/efc1983e-ae5e-11e1-b842-00144feabdc0. html\#axzz1wvFQ4vAL

82. Véase: Cuidado con los 'greenwashers'. Semana.com, septiembre 27 de 2012. Recuperado de: http:// www.semana.com/vida-moderna/cuidado-greenwashers/185474-3.aspx

83. "En tres décadas de explotación de la mina de níquel Cerro Matoso se han hecho ventas por 11.000 millones de dólares. Con tan fabulosa fortuna, ¿por qué los pueblos que la rodean siguen en la miseria y sus habitantes se quejan de extrañas enfermedades?" Ver: Cerro Matoso: mina rica, pueblo pobre. Semana.com, agosto 04 de 2012. En línea: http://www.semana.com/nacion/cerro-matosomina-rica-pueblo-pobre/182119-3.aspx

84. Dismantle Corporate Power. Propuesta para la elaboración de un Tratado Internacional de los Pueblos frente a la acción de las Empresas Transnacionales (ETN). Noviembre 14 de 2012. Recuperado de: http://www.stopcorporateimpunity.org/?p=2311\&lang=es 
que involucra crear valor económico de una manera que también cree valor para la sociedad al abordar sus necesidades y desafíos. Las empresas deben reconectar su éxito de negocios con el progreso social. El valor compartido no es responsabilidad social ni filantropía y ni siquiera sustentabilidad, sino una nueva forma de éxito económico. No está en el margen de lo que hacen las empresas, sino en el centro (Porter y Kramer, 2011: 3).

Este planteamiento parte del supuesto que

El capitalismo es un vehículo inigualable para satisfacer las necesidades humanas, mejorar la eficiencia, crear trabajo y generar riqueza. Pero una concepción estrecha del capitalismo ha impedido que las empresas exploten todo su potencial para satisfacer las necesidades más amplias de la sociedad (Porter y Kramer, 2011: 4).

El éxito de este enfoque reformista que, según los autores, está siendo implementado por empresas como GE, Google, IBM, Intel, Johnson \& Johnson, Nestlé, Unilever y Wal-Mart, está todavía en veremos, pues lo que se percibe es la continuidad de la política tradicional de las ETNs de explotar los recursos naturales y humanos en los países anfitriones, sin importar las consecuencias sociales y ambientales, se trata de un comportamiento esencialmente depredador.

En el aspecto jurídico, el andamiaje normativo a escala global, casi siempre favorece a las ETNs, lo que se refuerza con la legislación laxa de los países receptores, basada en la desregulación aperturista y contraria a los intereses nacionales. Incluso la Unión Europea está siendo objeto de demandas por parte de las ETNs, aprovechando la crisis por la que atraviesa, con cual buscan obtener mayores ganancias $^{\mathbf{8 5}}$.

En estas condiciones, la llamada responsabilidad social corporativa de las ETNs termina convirtiéndose en una desresponsabilización ${ }^{\mathbf{8 6}}$.

\section{CONCLUSIONES}

Las ETNs se han convertido en factor determinante de la profundización y orientación de la división internacional del trabajo, lo que a su vez ha contribuido al avance del proceso globalizador de la economía, controlado por unas cuantas potencias. El impacto del accionar de las ETNs sobre los países en desarrollo es

85. Ver: Cecilia Olivet y Pia Eberhardt. Profiting from Crisis . How corporations and lawyers are scavenging profits from Europe's crisis countries. Published by the Transnational Institute and Corporate Europe Observatory. Amsterdam/Brussels, March 2014. Recuperado de: http:/www.tni.org/sites/ www.tni.org/files/download/profiting_from_crisis.pdf

86. Ver: Juan Hernández Zubizarreta, Mikel dē la Fuente Lavín, Andrea De Vicente Arias y Koldo Irurzun Ugalde (editores). Empresas transnacionales en América Latina. Análisis y propuestas del movimiento social y sindical. Universidad del País Vasco. Hegoa-Omal. Junio de 2013. Recuperado de: https://www.fuhem.es/media/cdv/file/biblioteca/Boletin_ECOS/25/Empresas_transncionales_en_America_Latina.pdf p.14. 
no solo económico, sino también cultural, político, social, ético e ideológico. En lo económico, las ETNs han venido moldeando un modelo de inserción internacional de los países menos desarrollados, de acuerdo con los intereses de aquellas, convirtiéndolos en simples apéndices del capital extranjero, aparte del impacto negativo en el ambiente y del saqueo sistemático de los recursos naturales y la evasión fiscal.

En lo cultural la presencia de las ETNs en los países anfitriones menos desarrollados provoca un reemplazo creciente de valores, costumbres, hábitos de consumo, desplazamientos poblacionales, etc., por sus similares en los países dominantes. Las ETNs también influyen en la orientación política de los países, en busca del apoyo de gobiernos títeres a la estrategia expansionista de las potencias. En lo social, es bien conocida la explotación de la fuerza de trabajo en condiciones precarias y violación de los derechos humanos. En lo ético, las ETNs son un importante factor de corrupción, el cual se manifiesta en la compra de políticos y altos funcionarios públicos. En lo ideológico se profundiza la dependencia del conocimiento generado en los centros de pensamiento imperial en los países más desarrollados.

Finalmente, pese a toda la publicidad desplegada por las ETNs sobre la mal llamada responsabilidad social empresarial, el impacto de su accionar en los países en desarrollo será cada vez más negativo, impidiendo que estos últimos puedan desarrollarse teniendo en cuenta los intereses nacionales y no los del capital extranjero. 


\section{Referencias}

BLOMSTRÖM, Magnus and KOKKO, Ari (1996). The impact of foreign investment on host countries: a review of the empirical evidence. World Bank Policy Research, Working Paper No. 1745. Recuperado de: http://ssrn. com/abstract $=620572$

CORPORATE EUROPE OBSERVATORY (2014). The Fire power of the financial lobby. A survey of the size of the financial lobby at the EU level. CEO-AK-OGB, April. Recuperado de: http://corporateeurope.org/sites/default/ files/attachments/financial_lobby_report.pdf

DERECHOS Y DEMOCRACIA (2007). Estudio de los impactos de los proyectos de inversión extranjera en los derechos humanos. Recuperado de: http://www.bibliotecavirtual.info/2011/08/estudio-de-los-impactosde-los-proyectos-de-inversion-extranjera-en-los-derechos-humanos/

DENEAULT, Dominic (2012). The Transnational Corporation: developing the DNA of a global player. Dialogues International Growth-Caisse de dépôt et placement du Québec. Recuperado de: http://www.iberglobal. com/Archivos/dna_global_player_caisse_quebec.pdf

DOBBS, Richard; et al. (2013). Urban world: The shifting global business landscape. McKinsey Global Institute. October. Recuperado de: http://www.mckinsey.com/insights/urbanization/urban_world_the_shifting_global_business_landscape

DUNNING, John H.; SAUVANT, Karl P. (1993). The theory of transnational corporations. Preface. En : United Nations Library on Transnational Corporations, Volume 1. Recuperado de: http://unctc.unctad.org/data/ libvol1a.pdf

DUNNING, John H. (1993). Introduction: The nature of transnational corporations and their activities. En: United Nations Library on Transnational Corporations, Volume 1. Recuperado de: http://unctc.unctad.org/ data/libvol1a.pdf

ETC GROUP (2008). Who Owns Nature? Corporate Power and the Final Frontier in the Commodification of Life. Communiqué, Issue 100 November. Recuperado de: http://www.etcgroup.org/sites/www.etcgroup.org/files/ publication/707/01/etc_won_report_final_color.pdf

FOSTER, John B.; McCHESNEY, RobertW.; JONNA, R. Jamil (2011). The Global Reserve Army of Labor and the New Imperialism. Monthly Review, Volume 63, Issue 06 (November), pp.1-26. Recuperado de: http://monthlyreview. org/2011/11/01/the-global-reserve-army-of-labor-and-the-new-imperialism

Fortanier, Fabienne (2007). Foreign direct investment and host country economic growth: ¿Does the investor's country of origin play a role? Transnational Corporations, Vol. 16, No. 2, pp. 41-76. Recuperado de: http://www.unctad.org/en/docs/iteiit20072a2_en.pdf

GÖRG, Holger; STROBL, Eric (2003). Multinational Companies, Technology Spillovers, and Plant Survival. German Institute for Economic Research. Berlin. Discussion Papers, No. 366, pp. 1-20. Recuperado de: http:// ideas.repec.org/p/diw/diwwpp/dp366.html

HARDING, Torfinn; JAVORCIK, Beata Smarzynska (2009). A Touch of Sophistication: FDI and Unit Values of Exports. Econstor, Cesifo working paper No. 2865. Pp. 1-33. Recuperado de: http://hdl.handle.net/10419/30560.

HUTCHINSON, Francis (2003). Globalisation and the 'Newer' International Division of Labour. Labour and Management in Development, Volume 4, Number 6. Asia Pacific Press, pp. 1-24. Recuperado de: http://www.nla. gov.au/openpublish/index.php/Imd/article/viewFile/1194/1473. 
IWASAKI, Ichiro; SUGANUMA, Keiko (2009). EU enlargement and foreign direct investment into transition economies revisited. Transnational Corporations, Vol. 18, No. 3, pp. 27-57 Recuperado de: http://www.unctad. org/en/docs/diaeiia200912_en.pdf

JIMÉNEZ G., Dora E; RENDÓN O., Hernando (2011). Inversión extranjera directa en la industria manufacturera colombiana y spillovers de productividad. Ensayos de Economía, No. 39, Julio-Diciembre, pp. 49-71. Universidad Nacional de Medellín. Recuperado de: http://humanas.medellin.unal.edu.co/sites/default/files/ede/pdf/ ede_39/ede_39_03_jimenez_rendon.pdf

JONES, Geoffrey (2005). Multinationals and Global Capitalism. From the Nineteenth to the Twenty-First Century. Oxford University Press, New York.

MEYER, John P. (2008). Globalization and cultural imperialism: corporate control versus responsiveness. Journal of International Business and Economy, Volume 9 (1), pp. 113-136. Recuperado de http://www.i-jibe.org/ achive/2008spring/6-Meyer.pdf

MONGE, Jorge (2002). Industrial upgrading en el sector software en Costa Rica. En: PÉREZ S., Juan P (editor) (2002). Encadenamientos globales y pequeña empresa en Centroamérica. Flacso, Costa Rica, 336p.

OCDE (2010). Definición Marco de inversión extranjera directa. Cuarta edición 2008. Recuperado de: http:// www.oecd.org/daf/internationalinvestment/investmentstatisticsandanalysis/46226782.pdf

OXFAM (2013). Divide y comprarás: Una nueva forma de concentrar tierras baldías en Colombia. OXFAM-CRECE, septiembre, 40p. Recuperado de: http://www.oxfam.org/es/crece/policy/divide-y-comprar\%C3\%A1s

PERKINS, John (2005). Confesiones de un gánster económico. La cara oculta del imperialismo americano. Ediciones Urano, S.A. Barcelona, España. 278p.

PORTER, Michael E. y KRAMER, Mark R. (2011). La creación de valor compartido. Harvard Business Review, Enero-Febrero, Pp. 1-18. Recuperado de: http://www.filantropiatransformadora.org/attachments/article/198/ Shared\%20Value\%20in\%20Spanish.pdf

ROMERO, Alberto (2007). Desarrollo humano en el contexto de la globalización. Economía Gestión y Desarrollo, Pontificia Universidad Javeriana, Cali, No. 5, p. 269-294. Recuperado de: http://revistaeconomia.puj.edu.co/ $\mathrm{html} /$ modules.php? name=BookCatalog\&op=showbook\&bid $=61$

ROMERO, Alberto; VERA-COLINA, Mary A. (2012). La globalización posible: límites y alternativas. Cuadernos de Economía, FCE, Universidad Nacional de Colombia, Bogotá, 31(58), julio-diciembre de 2012, pp. 49-76.

UNTACD (2010). World Investment Report 2010: Investing in a Low-Carbon Economy. Recuperado de: http:// unctad.org/en/Docs/wir2010_en.pdf

UNTACD (2010a). Informe sobre las inversiones en el mundo 2010. Invertir en una economía de bajo carbono. Panorama general. Recuperado de: http://unctad.org/es/Docs/wir2010overview_sp.pdf

UNTACD (2011). Informe sobre las inversiones en el Mundo 2011. Formas no accionariales de producción internacionaly desarrollo. Panorama general. New York y Ginebra. Recuperado de: http://www1.unctad-docs.org/ files/UNCTAD-WIR2011-Overview-es.pdf (Consulta: julio 28-2011)

UNTACD (2011b). Informe sobre las inversiones en el mundo, 2011. Panorama general. Recuperado de: http:// www1.unctad-docs.org/files/UNCTAD-WIR2011-Overview-es.pdf

UNCTAD (2013). World Investment Report 2013: Global Value Chains: Investment and Trade for Development. United Nations. New York and Geneva. Recuperado de: http://unctad.org/en/PublicationsLibrary/wir2013_en.pdf

VITALI, Stefania; GLATTFELDER, James B.; BATTISTON, Stefano (2011). The network of global corporate control. Recuperado de : http://arxiv.org/PS_cache/arxiv/pdf/1107/1107.5728v2.pdf

ZARSKY, Lyuba; GALLAGHER, Kevin (2008). FDISpillovers and sustainable industrial development: evidence from U.S. firms in Mexico's Silicon Valley. Working Group on Development and Environment in the Americas. Discussion Paper Number 18. Recuperado de: http://ase.tufts.edu/gdae/Pubs/rp/DP18Zarsky_GallagherApr08.pdf 